Published in final edited form as:

Lancet. 2003 September 20; 362(9388): 996-997. doi:10.1016/S0140-6736(03)14375-9.

\title{
Catastrophic health expenditure
}

\author{
Jennifer Prah Ruger \\ Department of Medicine, Division of General Medical Sciences, Washington University School of \\ Medicine, St Louis, MO 63110, USA \\ Jennifer Prah Ruger: jruger@im.wustl.edu
}

Sir-Ke Xu and colleagues' article $^{1}$ raises important questions about health expenditure and the financial security of households, an issue that has, as noted by the authors, "long been ignored on the health policy agenda". Xu and co-workers' study adds to the evidence on the effect of health systems on households, and the time has come to put this and other research to use for effective policy making. We have learnt a lot about the equity and efficiency of health-care financing mechanisms, and a few key lessons are essential.

First, the uncertainty of health need, the catastrophic costs of medical care, and the riskaverse nature of individuals, places risk pooling at the centre of health-care financing. Collective arrangements for funding health care, such as health insurance, can protect individuals from financial loss when adverse health events arise. Individual risk is reduced by pooling a large number of people - the larger the risk pool the more precisely insurers can predict the probability of financial loss due to illness; therefore, the more accurately they can plan for, and spread, risk.

Health systems in many low-income and middle-income countries do not take advantage of the equity and efficiency that accrue from risk pooling through insurance. Common constraints include low individual incomes, high prevalence of informal incomes that escape taxation, and low administrative and tax-collection capacities. ${ }^{2}$ These constraints typically result in low amounts of health-care spending and risk-pooling, health-related capital stock — such as beds and drugs—and human resources—such as nurses and doctors.

Second, low-income countries, due to lower degrees of, and less targeted, public expenditure, are generally characterised by greater inequality in the distribution of financial and health-related resources than more developed countries. ${ }^{3}$ Direct payment (paying out-ofpocket) is the least equitable and efficient form of health-care payment. However, it is the primary means of financing health expenditure in many low-income and middle-income countries. Private insurance has been proposed as a solution, but while private insurance pools risks to a certain extent, it also attempts to segment and reduce risks, through selection of good risks to maximise profits. Regulation is needed to ensure that private health insurance maximises social-welfare benefits that can accrue from risk pooling.

Third, in general, public insurance (tax-financed or social insurance funds) tends to spread risk most efficiently (with large risk pools and low administrative costs). Public insurance also improves the odds of achieving both vertical equity-contributions to the cost of healthcare determined by income status, whereby richer individuals pay proportionately more than 
poorer individuals (through progressive financing where caps do not apply)—and horizontal equity-individuals in a particular income group, with the same ability to pay, contribute the same amount of health spending, irrespective of medical need. ${ }^{4}$

Efforts should be made worldwide to pool risks and provide health insurance to all. Without such measures, attempts to improve health will be undermined by both health and economic insecurity.

\section{Acknowledgments}

JPR is supported in part by a grant (1-K0IDA016358-01) from the US National Institutes of Health.

\section{References}

1. Xu K, Evans DB, Kawabata K, Zeramdini R, Klavus J, Murray CJL. Household catastrophic health expenditure: a multicountry analysis. Lancet. 2003; 362:111-17. [PubMed: 12867110]

2. Schieber, G.; Maeda, A. A curmudgeon's guide to financing health care in developing countries. In: Schieber, G., editor. Innovations in health care financing; Proceeding from World Bank conference; March 10-11, 1997;

3. WHO. World health report: health systems_-improving performance. Geneva: World Health Organization; 2000.

4. VanDoorslaer, E.; Wagstaff, A.; Rutten, F., editors. Equity in the finance and delivery of health care: an international perspective. New York: Oxford University Press; 1993. 